\title{
Effects of a filter at the mouth on pulmonary function tests
}

\author{
L. Fuso*, D. Accardo*, G. Bevignani*, E. Ferrante**, A. Della Corte*, R. Pistelli*
}

Effects of a filter at the mouth on pulmonary function tests. L. Fuso, D. Accardo, G. Bevignani, E. Ferrante, A. Della Corte, R. Pistelli. (C) ERS Journals Ltd 1995.

ABSTRACT: The aim of this study was to verify whether the increase of resistance to airflow using a filter at the mouth could determine significant systematic errors of measurement or change the diagnostic performance in a respiratory physiology laboratory.

The effect of the new filter Spirobac (DAR Spa, Italy) was assessed on out-patients referred to our laboratory for routine functional evaluation. The following tests were performed: maximal expiratory flow-volume curve, plethysmographic lung volume and airway resistance, bronchodilator test, and methacholine challenge test. Each test was performed randomly, twice with the filter and twice without.

Significant differences between measurements with and without filter were found for forced vital capacity, forced expiratory volume in one second, airway resistance, and specific airway conductance (sGaw). These differences were unrelated to the average values of the measurements, except for sGaw. The limits of agreement were within the range of intraindividual short-term repeatability for almost all of the function indices. The overall concordance between tests performed with and without filter was $\mathbf{7 8 \%}$ for bronchodilator test and $53 \%$ for methacholine test. However, in all the cases but one, the concordance of the methacholine test was inside the short-term repeatability.

We conclude that the filter Spirobac has a statistically significant effect on the results of some pulmonary function tests. However, this is not considered to be clinically significant, since the changes due to the filter were within the intraindividual variability of repeated measurements for almost all the function indices and no appreciable classification error was found in diagnostic tests.

Eur Respir J., 1995, 8, 314-317.
*Respiratory Physiology Dept, Catholic University, Rome, Italy.**Respiratory Physiology Dept, Military Hospital, Rome, Italy.

Correspondence: R. Pistelli

Fisiopatologia Respiratoria

Università Cattolica S. Cuore

Largo F. Vito 1

00168 Roma

Italy

Keywords:

Agreement between measurements

airflow resistance

short-term repeatability

Received: July 131994

Accepted after revision October 101994
The epidemiological importance of some airborne transmitted infections and the increasing frequency of immuno-deficient patients undergoing a pulmonary function assessment have raised the issue of microbial contamination of respiratory function instruments [1-4]. Although the role of spirometric equipment in the transmission of infections has not been clearly established [5], general recommendations and several precautions should be taken to avoid cross-contamination among patients [5, $6]$. One of the most frequently reported recommendations is the use of disposable filtering devices to prevent the deposition of aerosolized microdroplets derived from contaminated saliva and mucus inside the pulmonary function equipment. Unfortunately, a high filtering performance corresponds to a high viscous resistance to airflow. The question is, how much this increased resistance could affect the result of pulmonary function tests.

This study was planned in order to detect systematic differences between measurements of respiratory function indices made with and without a new disposable filter. Furthermore, the diagnostic concordance of bronchodilatation and bronchoconstriction tests performed with and without the filter was investigated.

\section{Materials and methods}

Respiratory function tests were performed on outpatients referred to our laboratory from their general practitioner for routine pulmonary function assessment. Thus, we examined both normal subjects and patients with pulmonary diseases, including asthma, chronic obstructive pulmonary disease and interstitial pulmonary disease. All patients fulfilling the American Thoracic Society (ATS) collaboration criteria $[6,7]$ were sequentially enrolled in our study, until an adequate number of measurements had been performed.

The filter Spirobac (DAR Spa, Italy) was tested. It contains the filtering system 3M GBS-50 (3M Filtration Products, St Paul, MN, USA) in a solid polypropylene housing directly connected to the spirometer or the pneumotachograph. The internal volume of the filter is 60 $\mathrm{ml}$, and the short connecting system determines only a negligible increase of the instrument dead space. The DAR laboratories showed that the filtering system provides a resistance to airflow of $0.08 \mathrm{cmH}_{2} \mathrm{O} \cdot l^{-1} \cdot \mathrm{s}$, which is linearly distributed over the entire physiological flow range $\left(0-12 l \cdot \mathrm{s}^{-1}\right)$. 
The effect of the filter Spirobac was evaluated on the following pulmonary function tests: maximal expiratory flow-volume curve, lung volume and airway resistance, bronchodilator test, and methacholine challenge test. The flow-volume curve was obtained by the pneumotachographic system Medgraphics 1070 (Medical Graphics Corp., St. Paul, MN, USA). The total lung volume and airway resistance were measured using the System 2800 Autobox (SensorMedics Corp, Anaheim, CA, USA), which employs a constant-volume plethysmograph. Lung volume measurements were corrected for the internal volume of the filter. The bronchodilator test was performed by repeating maximal expiratory flow-volume curves 30 min after inhalation of salbutamol $200 \mu \mathrm{g}$. The challenge test was performed by inhalation of aerosolized methacholine solutions, with concentrations increasing fourfold from 0.064 to $64 \mathrm{mg} \cdot \mathrm{ml}^{-1}$. Forced expiratory volume in one second $\left(\mathrm{FEV}_{1}\right)$ was recorded on a counterbalanced water-sealed light bell spirometer (Cosmed, Spa, Italy), and each test ended after the provocative concentration of methacholine solution which caused a $\mathrm{FEV}_{1}$ decrease $\geq 20 \%$ ( $\mathrm{PC}_{20}$ ), or after the inhalation of the last solution.

The resistances to airflow inside the pneumotachograph and the spirometer $\left(0.12\right.$ and $1.02 \mathrm{cmH}_{2} \mathrm{O} \cdot l^{-1} \cdot \mathrm{s}$, respectively) were so low that the total resistance of the systems, each comprising the instrument plus the filter, remained within the ATS specified upper limit of 1.5 $\mathrm{cmH}_{2} \mathrm{O} \cdot l^{-1} \cdot \mathrm{s}$. Moreover, the calibration characteristics of the instruments did not change with the addition of a resistance arranged in series, as the filter.

Four consecutive measurements of each functional index were collected in every patient: two performed with the filter, and two without, in random order. The measurements with and without filter of bronchodilator and methacholine tests were repeated in the same order at each step. Instruments were cleaned and sterilized after each patient, in order to prevent any contamination when performing tests without the filter.

In detail, measurements of forced vital capacity (FVC), $\mathrm{FEV}_{1}$, and forced mid-expiratory flow (FEF25-75) were obtained in 56 subjects ( 29 males and 27 females, aged $48 \pm 16 \mathrm{yrs}$ ). Total lung capacity (TLC) and residual volume (RV) were measured in 22 subjects (13 males and 9 females, aged $53 \pm 14$ yrs). Airway resistance (Raw) and specific conductance (sGaw) were recorded in 21 subjects (12 males and 9 females, aged $52 \pm 14$ yrs). A bronchodilator test was performed in 23 subjects ( 8 males and 15 females, aged $55 \pm 12 \mathrm{yrs}$ ), and the percentage change of $\mathrm{FEV}_{1}$ after salbutamol in comparison to the baseline value was considered as a measure of reversibility of airway obstruction. A methacholine challenge test was performed in 17 subjects ( 8 males and 9 females, aged $39 \pm 15 \mathrm{yrs}$ ), and the logarithmic slope of the curve obtained by plotting the percentage $\mathrm{FEV}_{1}$ changes versus methacholine concentration was considered as a measure of bronchial reactivity [8].

The difference between measurements with and without filter was tested first by analysis of variance (ANOVA), using presence of filter, gender and order of performance of each manoeuvre as main factors, whilst age, height and weight were used as covariates [9]. Since ANOVA showed no significant contribution of gender and order of performance of measurements, the only significant factor, i.e. the use of filter, was evaluated by a paired t-test after averaging the two measurements with filter and the two measurements without. The agreement between measurements with and without filter was assessed by plotting their differences against their mean values, according to the method proposed by BLAND and Altman [10] The limits of agreement, i.e. the range which includes $95 \%$ of the differences between the two methods [10], were also detected for each function index. Data from bronchodilator and methacholine challenge tests were included in two-way tables, and the Cohen's Kappa was calculated [11] to investigate the concordance between measurements with and without filter in the diagnosis of reversible

Table 1. - Comparison between measurements with and without filter

\begin{tabular}{|c|c|c|c|c|}
\hline PFT & Filter & & $\begin{array}{c}\text { Paired } \\
\text { t-test }\end{array}$ & p-value \\
\hline \multirow{2}{*}{$\begin{array}{l}\text { FVC } l \\
(n=56)\end{array}$} & Without & $3.79(0.17)$ & \multirow{2}{*}{3.15} & \multirow{2}{*}{0.002} \\
\hline & With & $3.73(0.16)$ & & \\
\hline \multirow[b]{2}{*}{$\begin{array}{l}\mathrm{FEV}_{1} l \\
(\mathrm{n}=56)\end{array}$} & Without & $2.90(0.14)$ & \multirow[b]{2}{*}{2.74} & \multirow[b]{2}{*}{0.008} \\
\hline & With & $2.87(0.14)$ & & \\
\hline \multirow[b]{2}{*}{$\begin{array}{l}\text { FEF25-75 } l \cdot \mathrm{s}^{-1} \\
(\mathrm{n}=56)\end{array}$} & Without & $2.58(0.18)$ & \multirow[b]{2}{*}{1.33} & \multirow[b]{2}{*}{ NS } \\
\hline & With & $2.55(0.18)$ & & \\
\hline \multirow[b]{2}{*}{$\begin{array}{l}\text { TLC } l \\
(\mathrm{n}=22)\end{array}$} & Without & $5.79(0.24)$ & \multirow[b]{2}{*}{-0.32} & \multirow[b]{2}{*}{ NS } \\
\hline & With & $5.81(0.25)$ & & \\
\hline \multirow[b]{2}{*}{$\begin{array}{l}\mathrm{RV} \quad l \\
(\mathrm{n}=22)\end{array}$} & Without & $1.94(0.10)$ & \multirow[b]{2}{*}{-0.41} & \multirow[b]{2}{*}{ NS } \\
\hline & With & $1.96(0.11)$ & & \\
\hline \multirow[b]{2}{*}{$\begin{array}{l}\text { Raw } \mathrm{cmH}_{2} \mathrm{O} \cdot l^{-1} \cdot \mathrm{s} \\
(\mathrm{n}=21)\end{array}$} & Without & $1.78(0.17)$ & \multirow{2}{*}{-2.94} & \multirow{2}{*}{0.008} \\
\hline & With & $1.97(0.16)$ & & \\
\hline \multirow{2}{*}{$\begin{array}{l}\mathrm{sGaw} \\
(\mathrm{n}=21)\end{array} \mathrm{s}^{-1} \cdot \mathrm{cmH}_{2} \mathrm{O}^{-1}$} & Without & $0.20(0.02)$ & \multirow[b]{2}{*}{3.47} & \multirow[b]{2}{*}{0.002} \\
\hline & With & $0.17(0.01)$ & & \\
\hline \multirow[b]{2}{*}{$\begin{array}{l}\Delta \mathrm{FEV}_{1} \quad \% \\
(\mathrm{n}=23)\end{array}$} & Without & $9.61(2.22)$ & \multirow[b]{2}{*}{-0.30} & \multirow[b]{2}{*}{ NS } \\
\hline & With & $9.81(2.30)$ & & \\
\hline \multirow{2}{*}{$\begin{array}{l}\text { Methacholine } \\
\text { log slope } \\
\% \mathrm{FEV}_{1} \cdot \mathrm{mg}^{-1} \cdot \mathrm{ml} \\
(\mathrm{n}=17)\end{array}$} & Without & $0.089(0.21)$ & \multirow{2}{*}{0.04} & \multirow{2}{*}{ NS } \\
\hline & With & $0.087(0.23)$ & & \\
\hline
\end{tabular}

Data are presented as mean, and SE in parenthesis. FVC: forecd vital capacity; $\mathrm{FEV}_{1}$ : forced expiratory volume in one second; FEF25-75: forced mid-expiratory flow; TLC: total lung capacity; RV: residual volume; Raw: airway resistance; sGaw: specific airway conductance; $\triangle \mathrm{FEV}_{1}$ : difference in $\mathrm{FEV}_{1}$ after salbutamol; Ns: not significant; PFT: pulmonary function test. 
airway obstruction and bronchial hyperreactivity. Three levels of response were considered to categorize the results of bronchodilator tests (increase in $\mathrm{FEV}_{1}$ lower than $7 \%$, between 7 and $10 \%$, and greater than 10\%) [12]. Categories for methacholine challenge tests corresponded to the last concentration inhaled.

\section{Results}

The comparison between measurements with and without filter are reported in table 1. Small, but significant differences were found for FVC, FEV , Raw and sGaw. When using the filter, FVC, FEV 1 and sGaw were reduced, whereas Raw was increased (table 1). The limits of agreement between measurements with and without filter are summarized in table 2 , and are graphically reported in figures 1 and 2 for $\mathrm{FEV}_{1}$ and sGaw, respectively. The differences between measurements with and without filter were homogeneously distributed over the entire range of measurements for all the function indices, as shown in figure 1 for $\mathrm{FEV}_{1}$, with the exception of sGaw, for which a clear positive relationship was found between differences and average values (fig. 2).

Table 2. - Mean differences and limits of agreement between measurements with and without filter

\begin{tabular}{|c|c|c|c|}
\hline \multirow[t]{2}{*}{ PFT } & \multirow{2}{*}{$\begin{array}{c}\text { Mean } \\
\text { differences }\end{array}$} & \multicolumn{2}{|c|}{ Limits of agreement } \\
\hline & & Upper & Lower \\
\hline $\mathrm{FVC} l$ & 0.05 & 0.31 & -0.21 \\
\hline $\mathrm{FEV}_{1} l$ & 0.03 & 0.21 & -0.15 \\
\hline FEF $25-75 \quad l \cdot \mathrm{s}^{-1}$ & 0.03 & 0.39 & -0.33 \\
\hline TLC $l$ & -0.02 & 0.52 & -0.56 \\
\hline $\mathrm{RV} \quad l$ & -0.02 & 0.44 & -0.48 \\
\hline Raw $\mathrm{cmH}_{2} \mathrm{O} \cdot l^{-1} \cdot \mathrm{s}$ & -0.18 & 0.38 & -0.74 \\
\hline $\mathrm{sGaw} \quad \mathrm{s}^{-1} \cdot \mathrm{cmH}_{2} \mathrm{O}^{-1}$ & 0.02 & 0.08 & -0.04 \\
\hline
\end{tabular}

For abbreviations see legend to table 1 .

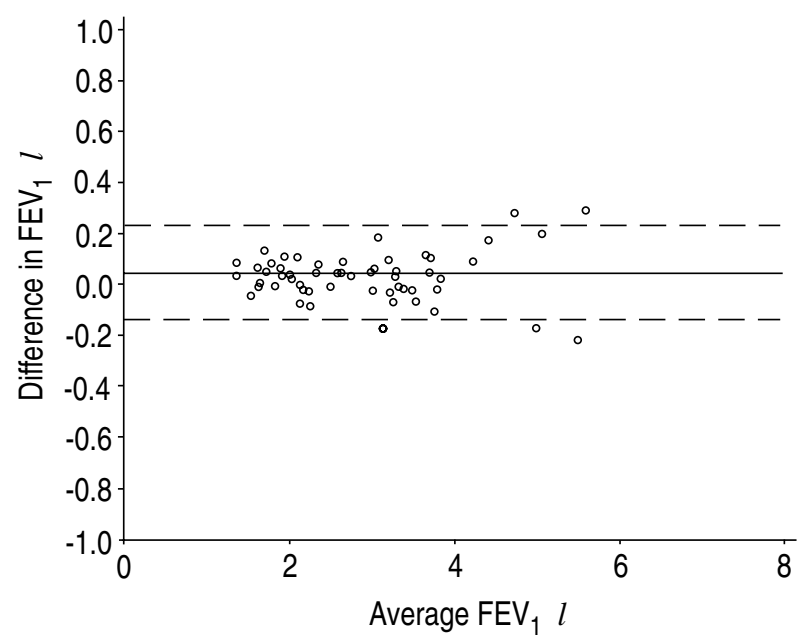

Fig. 1. - Agreement between measurements with and without filter. On the $\mathrm{x}$-axis are reported the average values of forced expiratory volume in one second $\left(\mathrm{FEV}_{1}\right)$ and on the $\mathrm{y}$-axis the differences between measurements without and with filter. The continuous line represents the mean difference; the dashed lines represent 2 standard deviations around the mean.

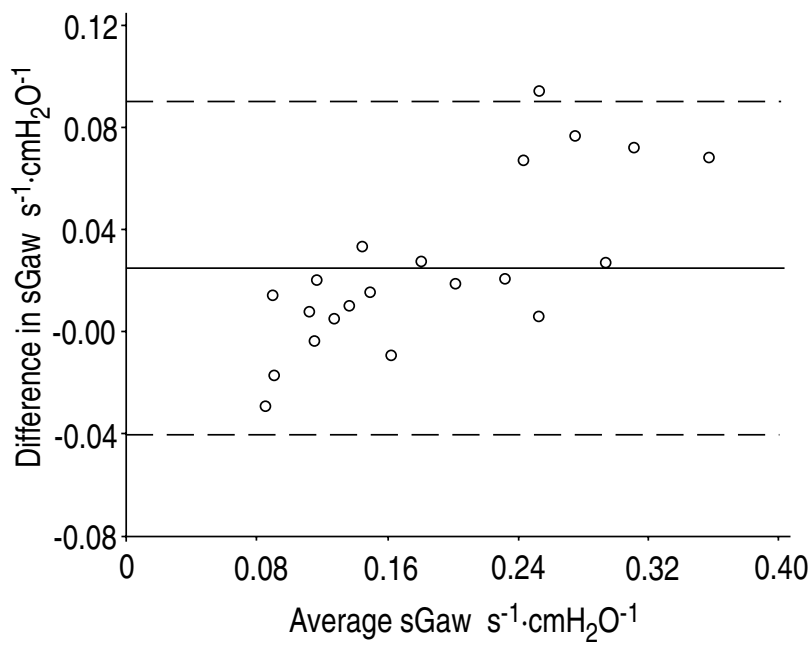

Fig. 2. - Agreement between measurements with and without filter. On the $\mathrm{x}$-axis are reported the average values of specific airway conductance (sGaw) and on the y-axis the differences between measurements without and with filter. The continuous line represents the mean difference; the dashed lines represent 2 standard deviations around the mean.

The classification of reversibility of airway obstruction was concordant in 18 out of 23 cases (78\%), with a Cohen's Kappa of 0.64 ; whereas, a concordant classification of bronchial reactivity was found in only 9 out of 17 cases $(53 \%)$, with a Cohen's Kappa of 0.47 .

\section{Discussion}

The use of a filtering device represents a real resistance to airflow interposed between patient and pulmonary function equipment. Therefore, real differences do exist between measurements performed with and without filter. Our study showed statistically significant differences only for FVC, $\mathrm{FEV}_{1}$, Raw, and sGaw, according to the $\mathrm{t}$-distribution (table 1). It is likely that the intraindividual variation of repeated measurements [13] was too high for most of the function indices to appreciate the small systematic differences introduced by the Spirobac filter. In routine laboratory activity, the measurement error is presumably higher than in our study and, therefore, systematic differences due to the filter should be less likely to be detected $[13,14]$.

To further compare measurements with and without filter, the method proposed by BLAND and Altman [10] was used. Indeed, measuring agreement may be more informative in comparing two methods of measurement than the more traditional correlation coefficient. In our study, the limits of agreement were satisfactory for almost all function indices (table 2). In detail, the limits of agreement for measurements of FVC, FEV ${ }_{1}$, and FEF25-75 were within the range of intraindividual short-term repeatability reported in the literature $[12,15]$. Limits of agreement for measurements of TLC and RV were slightly outside the range of the short-term repeatability $[12,16]$. This result could be attributed to the plethysmographic method that we used for lung volume measurements, which is affected by a larger error than the gas dilution 
method normally employed to study short-term reproducibility of lung volume measurements [12]. The limits of agreement for measurements of sGaw were also slightly greater than predicted on the basis of repeatability studies [16]. It is likely that the resistance added by the Spirobac filter to the equipment, can be a further source of error in measuring sGaw. Moreover, as clearly shown in figure 2 , a positive relationship was found between the differences in sGaw and their average values, the greater the former the greater the latter. This relationship was not explained by any classification factor of variance in our study design or by the lung pathology of the subjects. On the contrary, the same relationship was not found for all the other function indices, as shown in figure 1 for $\mathrm{FEV}_{1}$.

An error in diagnosis of bronchial reversible obstruction and bronchial hyperreactivity related to the use of a filtering device could represent a real problem in a respiratory physiology laboratory. Our data seem to show a greater lack of concordance in the diagnosis of bronchial hyperreactivity rather than in the diagnosis of bronchial reversible obstruction (Cohen's Kappa 0.47 versus 0.64 , respectively). However, when considering the short-term repeatability of methacholine challenge [17, 18 ], the $95 \%$ confidence interval for single measurements of PC20 in nonselected populations is $2-3$ twofold dose differences [19]. By applying this principle to our data, only one subject had clear discordant results between challenge tests with and without filter. Hence, the Spirobac filter produced only some minor diagnostic classification errors both for bronchodilator and methacholine tests.

In conclusion, this study showed that the Spirobac filter only marginally affected the measurements of respiratory function indices. The variations due to the filter were widely within the normal variability of repeated measurements for almost all function indices, and no appreciable classification error was found in diagnostic tests. Since filtering devices, such as Spirobac, do not introduce any systematic bias in the performance of respiratory physiology tests, our results should be considered as an encouraging incentive for their future use.

\section{References}

1. Hazaleus RE, Cole J, Berdischewsky M. Tuberculin skin test conversion from exposure to contaminated pulmonary function testing apparatus. Respir Care 1981; 26: 53-55.
2. Gough J, Kraak WAG, Anderson EC, Nichols WW, Slack MPE, McGhie D. Cross-infection by nonencapsulated Haemophilus influenzae. Lancet 1990; 336: 159-160.

3. Billing E. How should a respiratory function laboratory be made safe for use by patients with HIV infection and AIDS? Br Med $J$ 1991; 303: 576.

4. Canadian Thoracic Society. AIDS Memorandum, 1987.

5. Tablan OC, Williams WW, Martone WJ. Infection control in pulmonary function laboratories. Infect Control 1985; 6: 442-444.

6. American Thoracic Society. Standardization of spirometry: 1987 update. Am Rev Respir Dis 1987; 136: 1285-1298.

7. American Thoracic Society. Standardization of spirometry. Am Rev Respir Dis 1979; 119: 831-838.

8. O'Connor G, Sparrow D, Taylor D, Segal M, Weiss S. Analysis of dose-response curves to methacholine: an approach suitable for population studies. Am Rev Respir Dis 1987; 136: 1412-1417.

9. Snedecor GW, Cochran WG. Statistical methods. 6th edn. Ames, The Iowa State University Press, 1967.

10. Bland JM, Altman DG. Statistical methods for assessing agreement between two methods of clinical measurements. Lancet 1986; i: 307-310.

11. Sackett DL, Haynes RB, Tugwell P. Clinical epidemiology: a basic science for clinical medicine. Boston, Little Brown and Co., 1985.

12. Quanjer PhH, Tammeling GJ, Cotes JE, Pedersen OF, Peslin R, Yernault JC. Standardized lung function testing. Lung volumes and forced ventilatory flows: 1993 update. Eur Respir J 1993; 6 (Suppl. 16): 5-40.

13. American Thoracic Society. Lung function testing: selection of reference values and interpretative strategies. Am Rev Respir Dis 1991; 144: 1202-1218.

14. Coates AL, Desmond KJ, Demizio D, Allen PD. Sources of variation in $\mathrm{FEV}_{1}$. Am J Respir Crit Care Med 1994; 149: 439-443.

15. Pennock BE, Rogers RM, McCaffree DR. Changes in measured spirometric indices. What is significant? Chest 1981; 80: 97-99.

16. Zarins LP, Clausen JL. Body plethysmography. In: Clausen JL, ed. Pulmonary Function Testing Guidelines and Controversies. London, Grune \& Stratton, 1984; pp. 141-153.

17. Hargreave FE, Ryan G, Thomson NC, et al. Bronchial responsiveness to histamine or methacholine in asthma: measurement and clinical significance. J Allergy Clin Immunol 1981; 68: 347-355.

18. Juniper EF, Frith PA, Dunnett C, Cockcroft DW, Hargreave FE. Reproducibility and comparison of responses to inhaled histamine and methacholine. Thorax 1978; 33: 705-710.

19. Sterk PJ, Fabbri LM, Quanjer PhH, et al. Standardized lung function testing. Airway responsiveness. Eur Respir J 1993; 6 (Suppl. 16): 53-83. 